\title{
Water and Salt Balance in Agricultural Lands under Leaching with Shallow Subsurface Drainage Used in Combination with Cut-Drains
}

\author{
Yukio Okuda ${ }^{1,2, *}$, Junya Onishi ${ }^{2, *}$, Yulia I. Shirokova ${ }^{3}$, Iwao Kitagawa ${ }^{4}$, Yoshinobu Kitamura ${ }^{5}$ \\ and Haruyuki Fujimaki ${ }^{6}$ (D) \\ 1 Fukken Gijyutsu Consultants Co., Ltd., Sendai 980-0012, Japan \\ 2 Japan International Research Center for Agricultural Sciences (JIRCAS), Tsukuba 305-8686, Japan \\ 3 Research Institute of Irrigation and Water Problems (RIIWP), Tashkent 100187, Uzbekistan; \\ yulia_bonn@rambler.ru \\ 4 Institute for Rural Engineering, National Agriculture and Food Research Organization, \\ Tsukuba 305-8609, Japan; kitagaiw@affrc.go.jp \\ 5 Faculty of Agriculture, Tottori University, Tottori 680-8553, Japan; yoshikita1949@gmail.com \\ 6 Arid Land Research Center, Tottori University, Tottori 680-0001, Japan; fujimaki@tottori-u.ac.jp \\ * Correspondence: yukio756@sendai.fgc.co.jp (Y.O.); junya89@affrc.go.jp (J.O.); \\ Tel.: +81-22-217-2027 (Y.O.); +89-29-838-6634 (J.O.)
}

Received: 10 October 2020; Accepted: 10 November 2020; Published: 16 November 2020

\begin{abstract}
Secondary salinization of irrigated lands in drylands is often caused by rising groundwater levels. Open drainage is widely employed to control groundwater. However, salinity levels tend to remain high under malfunctioning drainage conditions. Shallow subsurface drainage may be a possible solution to prevent salt accumulation, although it is difficult for farmers to apply conventional tile drainage systems owing to construction costs. In this regard, we proposed a low-cost shallow subsurface drainage system used in combination with a new mole-drain drilling technology (cut-drain) developed in Japan, whose drainage capacity is similar to tile drain. The aim of this study is to evaluate the effect of the proposed system. The system was installed in a farmland, Uzbekistan. The experimental field was set with/without the system to observe the differences in the balance of water and salt. The results revealed that the remaining infiltrated water in the field decreased by approximately $26 \%$ and the removed net mass of salt was $14 \mathrm{Mg} \mathrm{ha}^{-1}$. The direction of salt movement changed from the deeper zone or surrounding field to the open drainage. Therefore, the proposed system can enhance salt removal from fields.
\end{abstract}

Keywords: salinization; desertification; subsurface drainage; water and salt balance; Uzbekistan

\section{Introduction}

Since the middle of the 20th century, agricultural productivity in the drylands of Central Asia has increased with irrigation development. During this period, drainage systems have also been installed to sustain the productivity of irrigated lands [1,2]. However, secondary salinization of irrigated lands has been occurring through rising groundwater level (GWL) caused by inefficient irrigation and malfunctioning drainage systems [3-5]. Salinization, one of the most significant drivers of desertification, puts the irrigated agriculture at risk in the long-term [6,7]. In 2015, the United Nations proposed the Sustainable Development Goals (SDGs). It lists the sustainable agriculture through combating desertification and promoting restoration of the degraded soil as one (No. 15) of the goals [8]. Drainage technology has played an important role to realize the sustainable agriculture. 
In Uzbekistan, which has the largest agricultural production in Central Asia, the drainage systems, which are mainly implemented with open, subsurface, and vertical drainages, have been deteriorating since the 1990s, following the dissolution of the Soviet Union. In 2007, the government of Uzbekistan inaugurated the Fund for Reclamation of Irrigated Lands to repair and replace these aging systems, resulting in satisfactory conditions in some areas [9]. However, the drainage systems are still in a state of disrepair in some areas [10]. Okuda et al. found that there were fields where salinity levels remained high [11]. Open drainage along the fields is widely employed to control groundwater. Although this method requires sufficient depth to discharge groundwater driven by a hydraulic gradient, incomplete dredging operations and inadequate maintenance have often caused increases in drainage water levels (DWL). Under such open drainage conditions, outlets from some deep subsurface drainages have been blocked by soil, leading to poor groundwater discharge from subsurface soil. Currently, the performance of vertical drainage systems is less efficient compared with that at the time of original construction in spite of massive energy requirement in contrast to other drainage systems $[12,13]$. Those drainage systems result in limited discharge and further salt accumulation. In addition to maintaining drainage systems, it is required to discharge accumulated salt to the open drainage regardless of the DWL.

Shallow subsurface drainage systems may be a possible solution for preventing salt accumulation. It can even be applied to farmland having open drainage degraded by sedimentation. Some studies conducted in Japan indicated that shallow subsurface drainage was an effective method for discharging saline water [14,15]. Previous studies in South Asia have examined the effects of relatively shallow subsurface drainage as a cost-effective technology [16]. However, in general, shallow subsurface drainage requires high drain pipe density, raising construction costs $[17,18]$. To solve this economic drawback, the current study presents an alternative of a low-cost shallow subsurface drainage used in combination with "cut-drains" (SSDC) as a new type of shallow subsurface drainage system. Cut-drains are constructed using a drain-drilling machine recently developed in Japan and have been used to enhance drainage, thereby preventing excessive water accumulation in the root zone of crop plants [19]. Cut-drain is a kind of mole drain. Generally, mole drains can improve soil permeability in the surface layer [20]. It has been used as a supplemental work to facilitate the effect of the main tile drain and not serving as the main drain because of its shallowness and small drainage capacity. Contrary, the depth of cut-drains is deeper than conventional mole drains and the drainage capacity is similar to tile drains. Therefore, cut-drains could replace most parts of tile drains to significantly lower the cost. Still, no study on the effect of the SSDC against secondary salinization has been carried out in the drylands. More studies are necessary for developing alternative low-cost drainage technology [21]. The purpose of this study is therefore to evaluate the effect of the SSDC in removing salt via analyzing water and salt balance in actual farmland with and without the SSDC.

\section{Materials and Methods}

\subsection{Outline of the Study Area}

The study site $\left(40^{\circ} 34^{\prime} 58^{\prime \prime}\right.$ N, $68^{\circ} 38^{\prime} 43^{\prime \prime}$ E) was located in Syrdarya Province, Uzbekistan (Figure 1). The aridity index of the site is 0.24 according to a previous study [22]. The average annual precipitation over the last 10 years is $334 \mathrm{~mm}$. Precipitation mainly occurs from October until April.

According to data collected by the Farmers' Council of Uzbekistan, the country had 4.3 million hectares (ha) of irrigated land in 2014. Currently, $47 \%$ of this land is affected by salinization defined as when the electric conductivity of a saturated extract (ECe) is larger than $2 \mathrm{dS} \mathrm{m}^{-1}$. Notably, in Syrdarya Province, salinization has extended over 280 kha which is $98 \%$ of the irrigated land. 


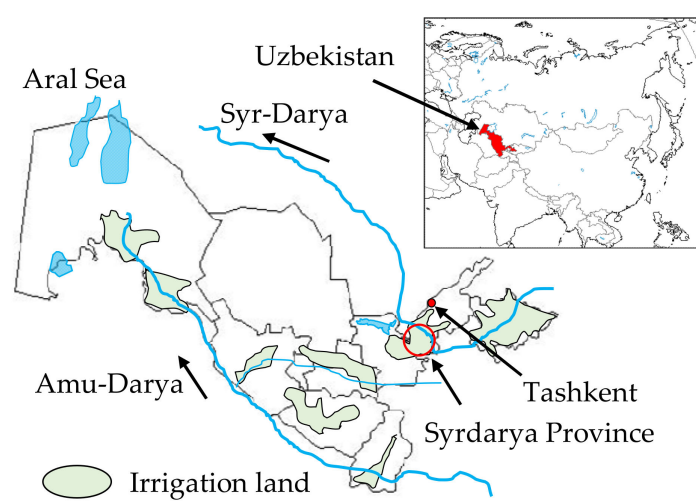

(a)

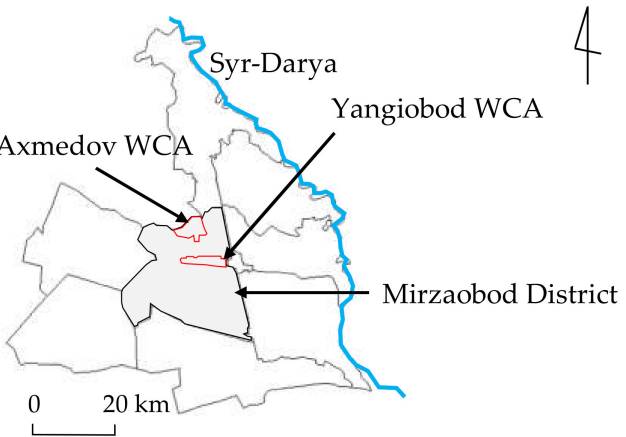

(b)

Figure 1. Location maps of the study site: (a) Irrigation land and Syrdarya Province in Republic of Uzbekistan; (b) Axmedov Water Consumers' Association (WCA) and Yangiobod WCA in Mirzaobod District, Syrdarya Province.

In Syrdarya Province, the Syr-Darya, an international river flowing along the eastern edge of the Province, is a main water resource for irrigation and leaching. In this region, main and branch irrigation canals are concrete-lined. The depth of the main open unlined drainages, referred to as "collectors," is approximately $3.0-4.5 \mathrm{~m}$ in general, and that of the lateral open drainages is approximately $2.0 \mathrm{~m}$ or less. Furrow irrigation is mainly used in the region [23]. Before the irrigation or leaching period, temporal field ditches are constructed to distribute water in the field. The field gradient is almost zero, although some parts in the field are undulating.

This study was conducted on a farm (approximately 30 ha) under commercial cultivation located in the Axmedov Water Consumers' Association (WCA, a non-governmental organization for water users [24]), Mirzaobod District, an area that has the highest salinity level in the province. The experimental field in the farm is mapped in Figure 2. According to our topographical survey, the field gradient from east to west is approximately $1 / 900$ on average. The soil is an alluvial soil and the textures are loam, sandy loam, and clay loam, according to the classification of the International Soil Science Society. The soil profile has a hard layer across $20-40 \mathrm{~cm}$. The layer has a low hydraulic conductivity and a high bulk density (Table 1).

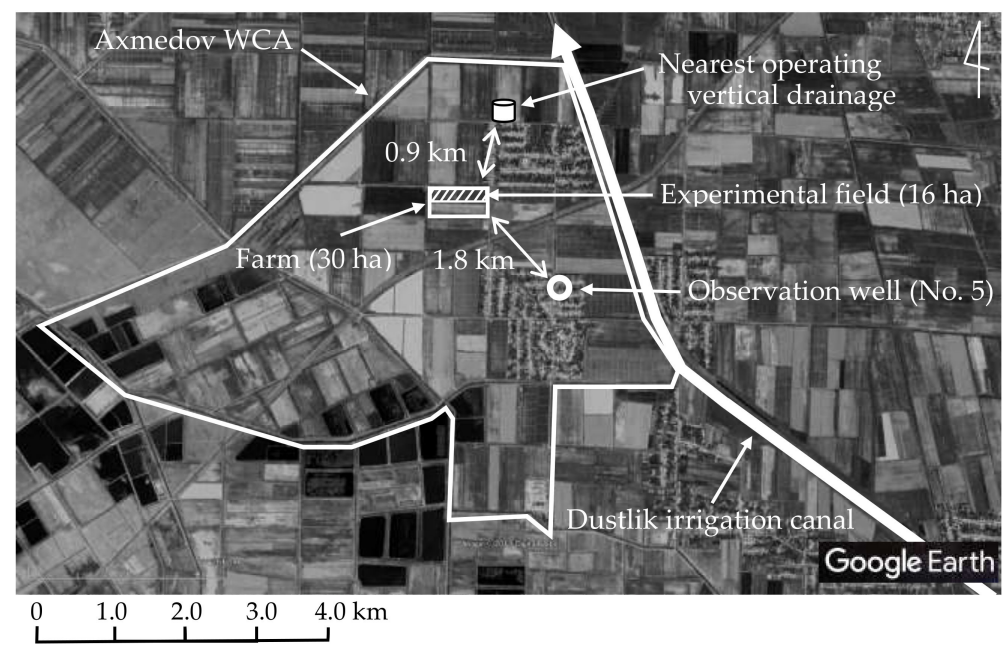

Figure 2. Location of the experimental field in Axmedov WCA. The figure shows the location of the nearest operating vertical drainage, observed well outside of the farm and the main irrigation canal, referred to as Dustlik irrigation canal. 
Table 1. Physical properties of soil in the experimental field.

\begin{tabular}{lcc}
\hline \multicolumn{1}{c}{ Layer } & $\begin{array}{c}\text { Ks } \\
\mathbf{c m ~ s}^{-\mathbf{1}}\end{array}$ & $\begin{array}{c}\text { Bulk Density } \\
\mathbf{g ~ c m}^{-\mathbf{1}}\end{array}$ \\
\hline Plow layer $(0-20 \mathrm{~cm})$ & $1.3 \times 10^{-5}$ & 1.60 \\
Hard layer $(20-40 \mathrm{~cm})$ & $5.0 \times 10^{-6}$ & 1.65 \\
Lower layer $(40-80 \mathrm{~cm})$ & $3.8 \times 10^{-5}-7.7 \times 10^{-5}$ & $1.45-1.54$ \\
\hline
\end{tabular}

Note: Sampling date is 28 February 2017. Ks is the saturated hydraulic conductivity determined using the falling head method.

The farm is surrounded by open drainages/ditches without tile drainage, and the nearest operating vertical drainage well is $0.9 \mathrm{~km}$ north from the farm. The open drainages on the north and east sides, parallel to community roads between the drainage and the farm, are relatively deep. The vertical difference between drainage bottom and field is approximately $2.0-3.0 \mathrm{~m}$. The open drainage on the western side, parallel to the embankment, is relatively shallow with approximately $1.5-2.0 \mathrm{~m}$ depth. On the southern side, a small sized ditch less than $1.0 \mathrm{~m}$ in depth was constructed between the farm and a next farm. During the leaching period in the winter season, the DWL rises by $0.5-1.0 \mathrm{~m}$.

Kitamura et al. showed limited groundwater flow to an open drainage under low hydraulic gradient conditions in the Lower Syr-Darya region [25]. In the present study, due to the low permeability of the soil, the presence of community road/embankment along the drainages, the insufficient drainage depth, and the long horizontal distance between the drainage and the field, the hydraulic gradient from the field to the open drainage became too small to function effectively as the drainage system [26].

\subsection{Experimental Set-Up}

Cut-drain construction is mainly characterized by a unique drilling method. The drilling machine towed by a tractor is used to excavate a conduit to a certain depth $(60-90 \mathrm{~cm})$. A cavity made by the drilling machine acts as a relatively stable mole drain as shown in Figure 3. Cut-drains can act as supplemental subsurface drains when used as a connection to the main tile drain. The discharge capacity is no different to the cut-drain and typical tile drain. A cut-drain is constructed without any additional material. The soil texture most appropriate for cut-drain construction is one with a high clay and low sand content. In case of loamy soils, durability of it is short [27].

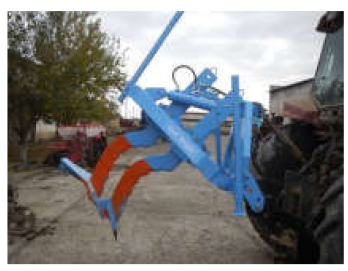

(a)

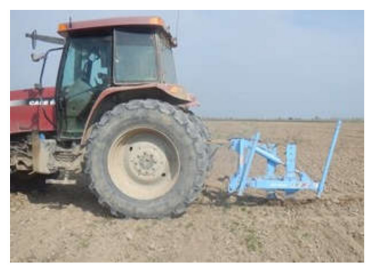

(b)

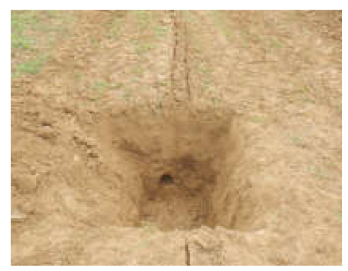

(c)

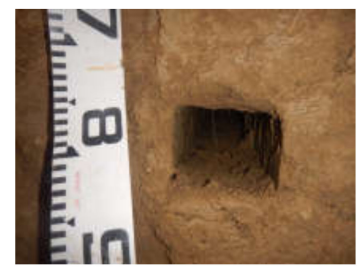

(d)

Figure 3. Construction of a cut-drain: (a) Equipped drilling machine; (b) towing the drilling machine; (c) cut-drain in soil profile (depth: 60-90 cm); and (d) constructed cut-drain (width: $10 \mathrm{~cm}$, height: $10 \mathrm{~cm}$ ).

The design of the experimental field in this study having an area of 16 ha on the farm is illustrated in Figure 4. Later in the year, the field was used to produce cotton. Before sowing cotton, the experimental field was divided into 65 leaching plots (13 rows in an east-west direction with 5 plots in a north-south direction). The area with the SSDC was 4.0 ha. In the SSDC field, two main tile drains comprised of a perforated pipe and rice husk, were installed in 2015 at a depth of approximately $1.0 \mathrm{~m}$. The diameter and length of the pipe were $10 \mathrm{~cm}$ and $200 \mathrm{~m}$, respectively. Using a tractor of 130-140 HP, cut-drains were constructed in 2015 and 2016 to a depth of $60-90 \mathrm{~cm}$ with a spacing of $5 \mathrm{~m}$. Since the cut-drain has a risk of preferential flow occurring which causes cavity collapse, we constructed it when the soil was wet along construction lines to mitigate the preferential flow in 2016 [28]. Cut-drains crossed the main 
tile drains to connect parts of the rice husk. The length of the cut-drains was $100 \mathrm{~m}$ on the east side of the main tile drain. The direction of the cut-drains was parallel to the field gradient from east to west. The area of the control field was set near the SSDC field.

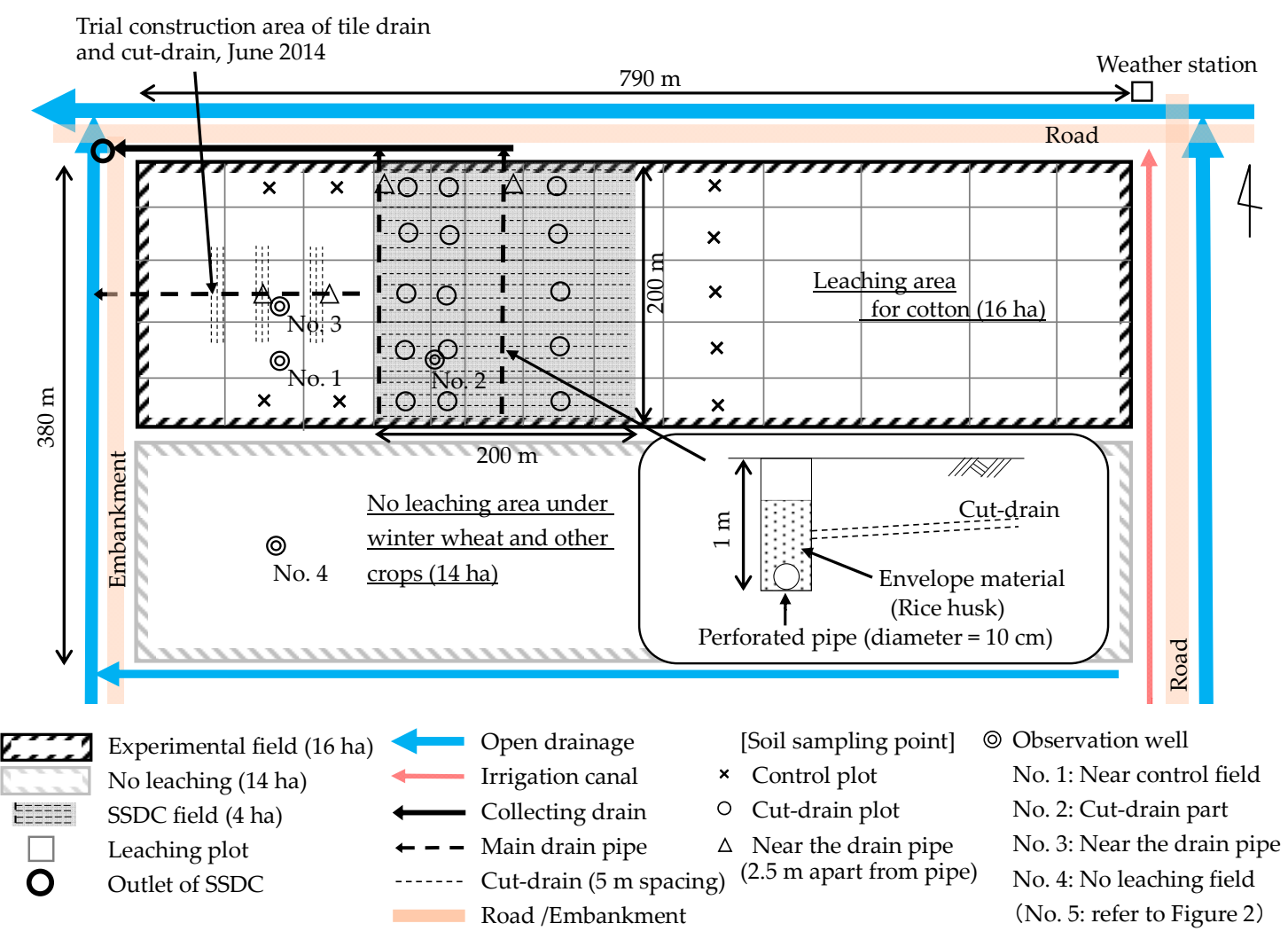

Figure 4. Layout of the experimental field on the farm. The figure shows the location and cross-sectional drawing of the shallow subsurface drainage used in combination with "cut-drains" (SSDC) field. The sampling points are shown in the plot of the control field, cut-drain part and near the drain pipe. The locations of four observation wells are shown by each number.

To observe soil moisture and salinity, soil samples in the cut-drain part and the control field were taken at the center of 15 plots and 9 plots, respectively, which were less affected by other factors such as tile drain or partial construction of cut-drain, and 4 points in the area near the drain pipe (a point $2.5 \mathrm{~m}$ distant from the pipe).

To observe fluctuation of groundwater depth, five observation wells using perforated pipes were installed to the depth of $4.5 \mathrm{~m}$ from the ground surface. Using these wells, the GWLs were monitored at each point in the control field (No. 1), the cut-drain part (No. 2), and the area near the drain pipe (No. 3). In addition, to compare the groundwater fluctuation between with and without leaching, two GWLs (No. 4 and No. 5) were also monitored. Point No. 4 was installed at a distance of $70 \mathrm{~m}$ from the experimental field in the same farm under winter wheat. No. 5 was installed at a distance of approximately $1.8 \mathrm{~km}$ from the experimental field, where there was no field under leaching nearby (Figure 2). The GWLs were observed using water level loggers (Model HOBO-U20-001-04-TI, Onset Computer Corporation, Bourne, MA, USA) put into the wells. A barometer using the same model was also set near the field to calculate the GWL. 


\subsection{Analysis}

\subsubsection{Water and Salt Balance}

Kitamura et al. analyzed the water balance in an irrigated area of the lower Syr-Darya region of the Aral Sea Basin for a certain period [25]. We modified their water balance equation as follows:

$$
\begin{aligned}
\Delta & =\mathrm{Ws} 2-\mathrm{Ws} 1 \\
& =\mathrm{W} i+\mathrm{W} r+\mathrm{W} g 1-\mathrm{W} g 2-\mathrm{Wg} 3-\mathrm{Wg} 4-\mathrm{W} d-\mathrm{Wet}
\end{aligned}
$$

where $\Delta$ is the difference in storage in the root zone to the depth of $100 \mathrm{~cm}$ between before and after leaching $(\mathrm{mm}), \mathrm{W}$ is the amount of each process $(\mathrm{mm})$. Subscripts $s 1$ and $s 2$ represent the storage in the soil before and after leaching, respectively, $i$ is applied water for leaching, $r$ is rain, $g 1$ is groundwater inflow to the root zone, $g 2$ is groundwater outflow from the outlet of the SSDC, $g 3$ is seepage from the field to the open drainage, $g 4$ is groundwater outflow from the root zone through paths other than $g 2$ and $g 3$, which is not emerged to open drainage but flowing vertically into deeper zone or horizontally into the neighboring dry field driven by hydraulic head, $d$ is surface drainage water from the field, and $e t$ is the evapotranspiration (ET).

Since there is no surface drainage flow from the field, $\mathrm{Wd}$ can be disregarded and Equation (1) can be rearranged as follows:

$$
\mathrm{Ws} 2+\mathrm{Wg} 4=\mathrm{W} i+\mathrm{W} r+\mathrm{Wg} 1-\mathrm{Wg} 2-\mathrm{Wg} 3-\mathrm{Wet}+\mathrm{W} s 1
$$

The left hand side is regarded as remaining water after leaching. By definition, Ws 2 is the amount of water stored in the root zone $(0-100 \mathrm{~cm})$. Wg4 is outflow from this zone. Therefore, the remaining water does not include the initially stored water in the deeper zone or neighboring dry field.

Using Equation (2), the salt balance is expressed as follows:

$$
\mathrm{Ss} 2+\mathrm{S} g 4=\mathrm{S} i+\mathrm{S} r+\mathrm{S} g 1-\mathrm{S} g 2-\mathrm{S} g 3+\mathrm{S} s 1
$$

where $S$ is the amount of salts $\left(\mathrm{Mg} \mathrm{ha}^{-1}\right)$, calculated by multiplying the amount of water $\left(1 \mathrm{~mm}=10 \mathrm{~m}^{3} \mathrm{ha}^{-1}\right)$ and salt concentration $\left(1 \mathrm{~g} \mathrm{~L}^{-1}=10^{-3} \mathrm{Mg} \mathrm{m}^{-3}\right)$. Subscripts are the same as above. Note that the ET term is disregarded in the salt balance equation.

The left hand side expresses a remaining salt mass after leaching. The effect of salt removal using the SSDC system is shown by comparison with the control field based on the calculation results of Equation (3).

\subsubsection{Measurement/Presumption of Data}

- $\quad$ Soil moisture: Ws1, Ws2

Soil samples were taken from five layers (0-20, 20-40, 40-60, 60-80, and 80-100 cm) using an auger. The numbers of samples taken from the control field, the cut-drain part, and the area near the drain pipe (a point $2.5 \mathrm{~m}$ distant from the pipe) were 45,75 , and $20(9,15$, and 4 sets), respectively.

- $\quad$ Leaching water: $\mathrm{W} i$

The average current velocity $\left(\mathrm{m} \mathrm{s}^{-1}\right)$ and its section area $\left(\mathrm{m}^{2}\right)$ were measured at upstream points in the temporal canals of the field once a day. The current velocity was measured using an electro-magnetic current meter (Model LP30, KENEK Corporation, Tokyo, Japan).

- Precipitation: $\mathrm{W} r$

Precipitation was measured at a farmer's garden located at a distance of $60 \mathrm{~m}$ to the north of the experimental field using a weather station (Model Vantage Pro2, Davis Instruments Corporation, Hayward, CA, USA). 
- Groundwater inflow to the root zone $(0-100 \mathrm{~cm})$ from outside: $\mathrm{W} g 1$

Horizontal inflow toward the root zone can be disregarded because the field was surrounded by drainages and the surrounding field was relatively dry. Consequently, to determine Wg1, we presumed upward flow from groundwater toward the root zone.

- Groundwater outflow from SSDC: $\mathrm{Wg} 2$

The discharge volume was estimated by measuring the volume poured from the outlet pipe using a bucket once a day.

- $\quad$ Seepage from the field to the open drainage: $\mathrm{Wg} 3$

It was difficult to measure and determine the actual seepage from the experimental field to the open drainage. The seepage rate was estimated using a value which was derived by analyzing the composition of the open drainage water. In 2012, we observed the amount and salinity of open drainage, and the salinity of groundwater and irrigation water in Yangiobod WCA (Figure 1b) similar to Axmedov WCA, whose fields are not equipped with subsurface drainage systems, in Mirzaobod District. Simultaneously, we also obtained the amount of distributed irrigation water and precipitation from local organizations. Using these data, we estimated the seepage rate (Table S1) [29].

- Evapotranspiration: Wet

Literature data for Syr-Darya River Basin, showing the reference evapotranspiration (ET0) every ten days [22], were applied to estimate the Wet.

- $\quad$ Salinity in the water: $\mathrm{Si}, \mathrm{Sr}, \mathrm{Sg} 1, \mathrm{Sg} 2, \mathrm{Sg} 3$

Samples of canal water used for leaching (Si), rain water (Sr), and the SSDC outflow (Sg2) were collected during the observed period. The sampling days of $\mathrm{Si}, \mathrm{S} r$, and $\mathrm{Sg} 2$ were twice in the first leaching and once in the second, at four rainy days, and every day during the water supply and then approximately once every ten days in the later period, respectively. The EC $w$ was measured using an EC meter (EC-33B, HORIBA Advanced Techno, Kyoto, Japan). Occasionally, total dissolved solids in the water (TDS, $\mathrm{g} \mathrm{L}^{-1}$ ) was analyzed to estimate the mass of salts. Here, EC $w$ of the other groundwater ( $\mathrm{Sg} 1$ and $\mathrm{Sg} 3$ ) is also assumed to be the same as that of the SSDC outlet water.

- $\quad$ Salinity in the soil: Ss1, Ss2

The electrical conductivities of a 1:1 suspension (EC1:1) of sampled soils were measured. Each EC1:1 value was converted to ECe using an empirical formula presented by the Research Institute of Irrigation and Water Problems of Uzbekistan [30]. To estimate the salt balance, TDS volume in the soil (TDSsoil), expressed in terms of mass percentage, before and after leaching was analyzed. TDSsoil is determined by a percentage of TDS weight in 1:5 suspension to the dry soil weight. The change in soil salinity was evaluated with an analysis of variance method.

\section{Results}

\subsection{Data Analysis}

- $\quad$ Soil moisture: Ws1, Ws2

Soil samples were taken before leaching on 19 and 20 December 2016, and after leaching on 27 and 28 February 2017. The volumetric water contents before and after leaching are shown in Figure 5 . Soil moisture was horizontally uniform before leaching while those of surface and bottom layers were higher than that of the middle layer. During leaching, all plots were flooded, and at the end of February 
when 1.5 months from the final day of leaching had passed, moisture levels remained high in almost the entire root zone. The only exception in this case was the surface layer $(0-20 \mathrm{~cm})$ near the drain pipe.

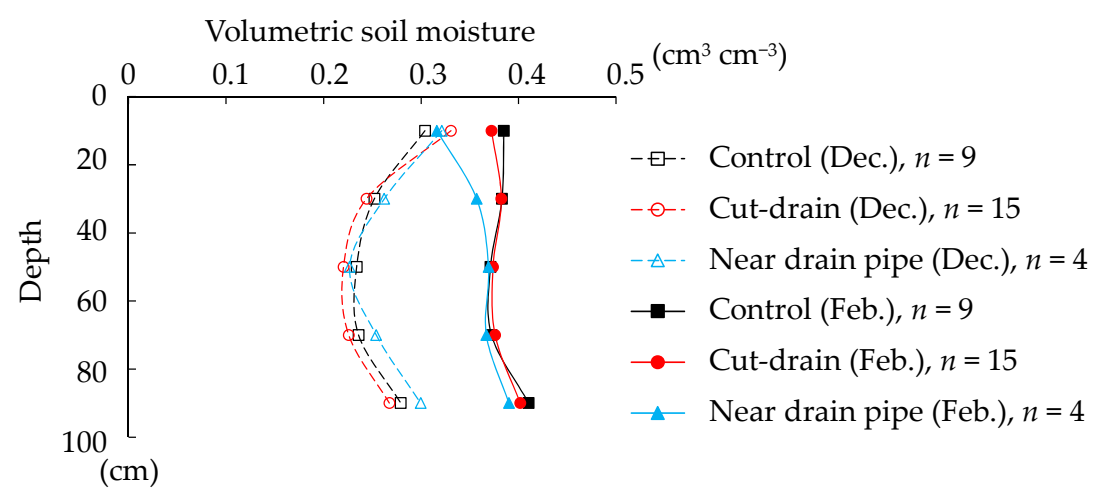

Figure 5. Changes in soil moisture before and after leaching. The figure shows soil moisture for each layer of $20 \mathrm{~cm}$ before and after leaching. The $n$ represents the number of sampling plots. The data were the average values in the control field, cut-drain part, and near the drain pipe, respectively.

The stored water in the root zone before and after leaching was 261 and $384 \mathrm{~mm}$ in the control field, and 259 and $379 \mathrm{~mm}$ in the SSDC field, respectively.

- $\quad$ Leaching water: $\mathrm{W} i$

Leaching in the experimental field was carried out twice according to the WCA's water distribution plan. The first leaching was conducted from 21 at 11 a.m. to 29 at 11 a.m. December 2016, and the second from 3 at 11 a.m. to 12 at 4 p.m. January 2017. In the SSDC field, leaching was carried out from 25 at 10 a.m. to 27 at 9 p.m. December 2016, and then restarted from 6 at 6 p.m. to 11 at 6 p.m. January 2017. The depths of the first and second leaching were 192 and $118 \mathrm{~mm}$, respectively, resulting in a $310 \mathrm{~mm}$ of total leaching.

- Precipitation: $\mathrm{Wr}$

The precipitation was $127 \mathrm{~mm}$ during the 70 days.

- Groundwater inflow to the root zone from outside: Wg1

The changes in GWL are shown in Figure 6. Before leaching, all GWLs had similar rising rates. The GWLs at No. 1-3 suddenly rose up to the depth of 10-60 cm during the first leaching, then, repeated up and down in the zone of 0 to $100 \mathrm{~cm}$. The changes in GWL were influenced by leaching and rain events. The GWL at No. 4 slightly enhanced the rising after leaching until the middle of January, then, rising rate increased, and finally synchronized to the other wells in the field at the beginning of February. The GWL of No. 4 seems to be linked to the leaching. The GWL at No. 5, where there was no field under leaching nearby, kept an equal rising rate at approximately $10 \mathrm{~mm}$ per day until the end of January. This rising rate might be a natural fluctuation. Excluding rains, the rising rate was nearly constant until the end of February. Applying this rising rate of No. 5 to No. $1-4$, the GWLs would not have reached to the depth of $100 \mathrm{~cm}$ during the 70 days if leaching had not been carried out. Consequently, we may neglect the upward groundwater inflow into the root zone (i.e., $\mathrm{Wg} 1=0$ ). 


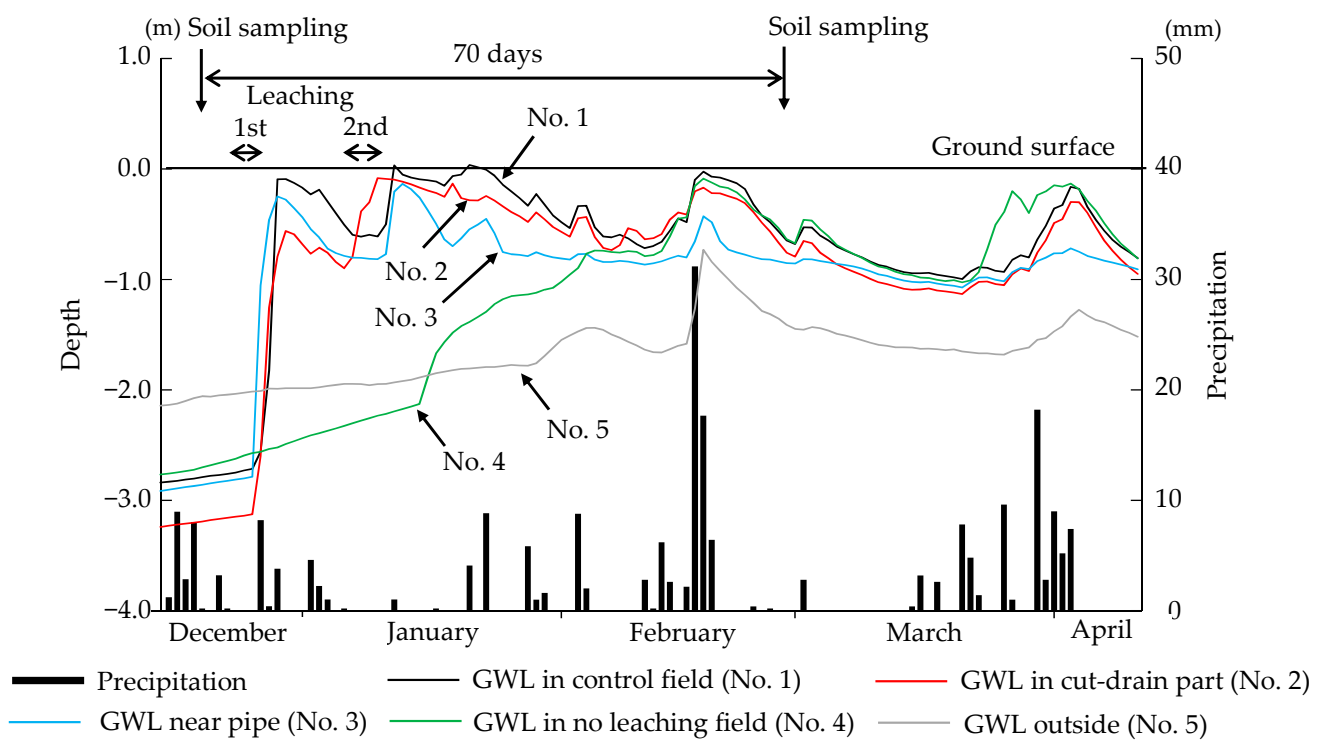

Figure 6. Changes in groundwater level and precipitation. Note: The GWLs show averages for $24 \mathrm{~h}$. The height of ground surface corresponds to that of each observation well point. The lines and bars show the GWL from the ground surface and precipitation, respectively.

- Groundwater outflow from SSDC: Wg2

The discharge rate at the outlet is shown in Figure 7, along with leaching water and precipitation. The outlet was closed during the first leaching period to ensure sufficient time to soak the soil with leaching water. Nine hours after completion of water supply in the first leaching, discharge started. The outlet was opened on 30 December after a lapse of sixty hours from the completion of the leaching, and measurement of the discharge rate was commenced. Therefore, discharge rate measured on the first day also included the discharge accumulated from previous two days. Although some data were missing, the total discharge for the 70 days was $149 \mathrm{~mm}$, corresponding to $34 \%$ of the applied water.

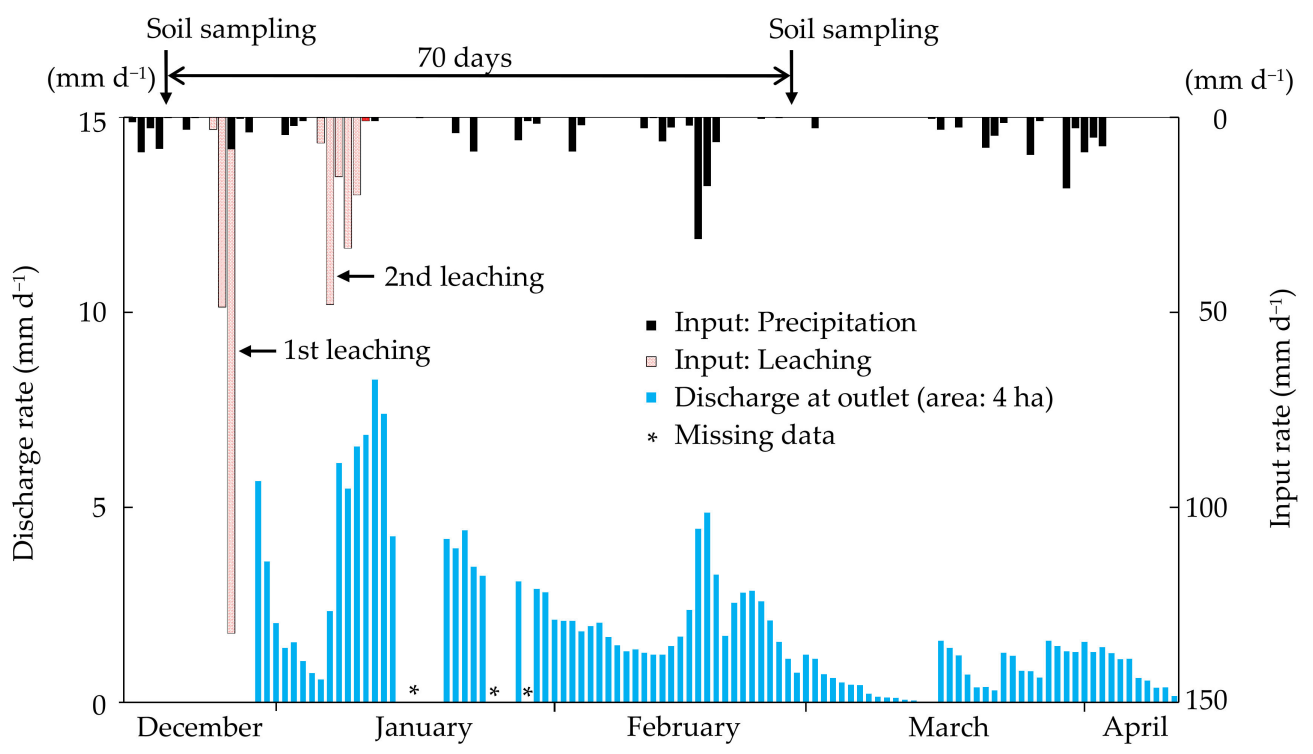

Figure 7. Amounts of discharged water and input water in the SSDC field. The horizontal axis is date and the upper side shows the input water for leaching and precipitation and the lower shows the discharged water from the SSDC outlet. The asterisks indicate missing data in the discharged water. 
- Seepage from the field to the open drainage: $\mathrm{Wg} 3$

Because the input water during the period was $437 \mathrm{~mm}$, the amount of groundwater outflow by seepage $(\mathrm{Wg} 3)$ was estimated to be $52 \mathrm{~mm}$, assuming that the same portion, $12 \%$, of applied water seeped out. It was approximately one-third of the groundwater outflow from the SSDC (Wg2). The lower seepage amount may be attributed to the low hydraulic gradient.

\section{- Evapotranspiration: Wet}

According to Bezborodov et al. [22], the ET0 ranges between 0.4 and $0.8 \mathrm{~mm} \mathrm{~d}^{-1}$ in December and January, and 1.0 and $1.5 \mathrm{~mm} \mathrm{~d}^{-1}$ in February in Syr-Darya River Basin. Assuming that the evaporation rate is the same as ETO during leaching period in the rainy season, the total ET for the 70 days was approximately $56 \mathrm{~mm}$.

\section{- $\quad$ Salinity in the water: $\mathrm{Si}, \mathrm{Sr}, \mathrm{Sg} 1, \mathrm{Sg} 2, \mathrm{Sg} 3$}

The average EC $w$ of leaching water for $\mathrm{Si}$, rain water for $\mathrm{S} r$, and the discharged water from the SSDC for Sg2 during the 70 days were $1.2,0.3$, and $10.2 \mathrm{dS} \mathrm{m}^{-1}$, respectively. The EC $w$ was converted to the total salt mass in the water using an empirical formula determined using the data collected on the farm (Figure 8a,b). The total salt of input ( $\mathrm{Si}$ and $\mathrm{Sr}$ ) and discharged water (Sg2) was 3.3 and 17.2 $\mathrm{Mg} \mathrm{ha}^{-1}$ during the 70 days, respectively, indicating that $13.9 \mathrm{Mg} \mathrm{ha}^{-1}$ of salts could be removed through the SSDC. The upward salt flux to the root zone could be neglected due to the absence of upward flow to the root zone (i.e., Sg1 $=0$ ). Regarding the seepage, we assumed that the seeped water had the same ECw as the discharged water from the outlet of the SSDC, resulting in $6.0 \mathrm{Mg} \mathrm{ha}^{-1}$ of $S g 3$.

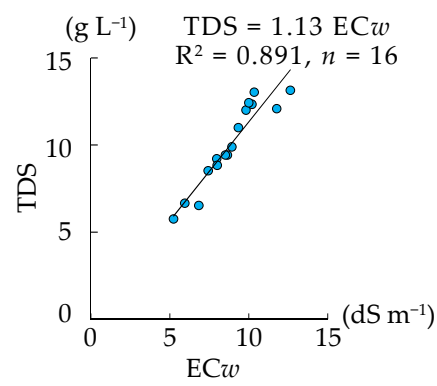

(a)

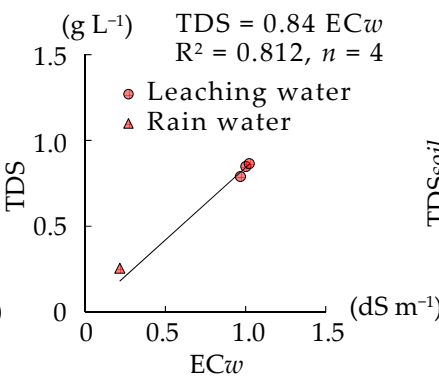

(b)

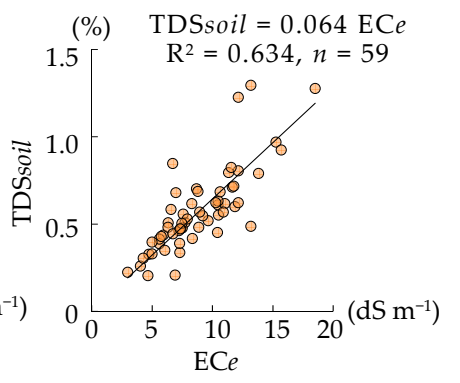

(c)

Figure 8. Correlation between electrical conductivity (EC) and total dissolved solid (TDS): (a) ECw and TDS in discharged water from the outlet of SSDC; (b) ECw and TDS in leaching water from canal and rain water; (c) ECe and TDSsoil in sampled soil. Note: The samples for analysis were taken on the same farm, and the days of sampling were (a) in December 2015, January 2016, January and February 2017, (b) in January 2016 and January 2017, and (c) in December 2016 and February 2017.

- $\quad$ Salinity in the soil: Ss1, Ss2

The average ECe analyzed from the upper $(0-60 \mathrm{~cm})$ and lower layer $(60-100 \mathrm{~cm})$ before and after leaching are shown in Figure 9. The figures above the bars show the ECe and the figures in parentheses show the percentage of the $\mathrm{EC} e$ after leaching compared with the corresponding value before leaching. The relative changes in soil salinity in the control field, the cut-drain part, and the area near the drain pipe were $67 \%, 62 \%$, and $50 \%$ in the upper layer, and $85 \%, 87 \%$, and $62 \%$ in the lower layer, respectively. There were no significant differences under the analysis of variance. Obtained ECe values were converted to TDSsoil using an empirical formula shown in Figure 8c. We found that the total salt mass in the root zone changed before and after leaching were 93.4 and $69.7 \mathrm{Mg} \mathrm{ha}^{-1}$ in the control field, and 85.4 and $60.4 \mathrm{Mg} \mathrm{ha}^{-1}$ in the SSDC field, respectively. Therefore, the total reduction in salt mass owing to leaching in the control and the SSDC field were 23.7 and $25.0 \mathrm{Mg} \mathrm{ha}^{-1}$, respectively. 

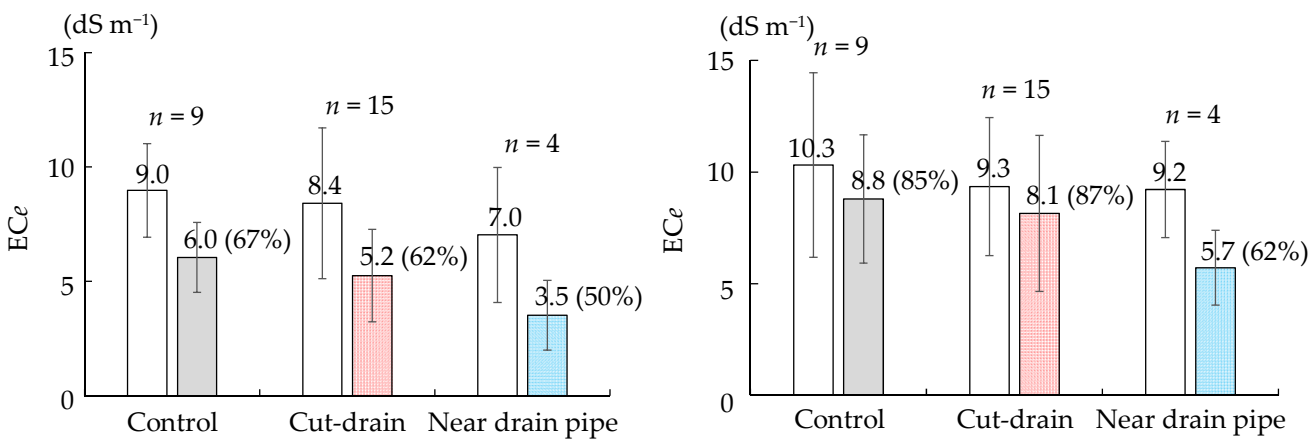

Before leaching, sampling date: 19-20 December 2016

$\square \square \square$ After leaching, sampling date: 27-28 February 2017

(a)

(b)

Figure 9. Changes in soil salinity before and after leaching: (a) Upper layer $(0-60 \mathrm{~cm})$; (b) lower layer $(60-100 \mathrm{~cm})$. Error bars represent the standard deviation. The figure above the bar shows the ECe. The figures between parentheses show the percentage of ECe after leaching to that before leaching. The $n$ represents the number of the sampling points. The analysis of variance resulted in no significant differences $(p<0.05)$.

\subsection{Water and Salt Balance}

- Remaining water in the fields: Ws2 $+\mathrm{Wg} 4$

The result of water balance calculation is listed in Table 2. The remaining amount of water, which was not discharged to open drainage, was $590 \mathrm{~mm}$ for the control field and $439 \mathrm{~mm}$ for the SSDC field. The main difference in remaining water occurred in the $\mathrm{Wg} 4$. The $\mathrm{Wg} 4$ of the SSDC field was $71 \%$ lower than that of the control field.

Table 2. Water and salt balance with/without the SSCD during the leaching period.

\begin{tabular}{|c|c|c|c|c|c|c|c|c|c|c|}
\hline \multirow[b]{2}{*}{ Treatment } & \multirow[b]{2}{*}{ Input } & \multirow[b]{2}{*}{$\begin{array}{l}\text { Groundwater } \\
\text { Inflow }\end{array}$} & \multirow[b]{2}{*}{$\begin{array}{l}\text { Outlet of } \\
\text { SSDC }\end{array}$} & \multirow[b]{2}{*}{$\begin{array}{l}\text { Seepage to } \\
\text { Drainage }\end{array}$} & \multirow[b]{2}{*}{ ET } & \multicolumn{3}{|c|}{ Root Zone 0-100 cm } & \multicolumn{2}{|c|}{ Remaining Portion } \\
\hline & & & & & & Before Leaching & After Leachi & Diff. & $\begin{array}{l}\text { Total in } \\
\text { Field }\end{array}$ & $\begin{array}{l}\text { Outside of } \\
\text { the Zone } \\
0-100 \mathrm{~cm}\end{array}$ \\
\hline & $\mathrm{W} i+\mathrm{W} r$ & $\mathrm{Wg1}$ & $\mathrm{Wg} 2$ & $\mathrm{Wg} 3$ & Wet & Ws1 (\%) & Ws2 (\%) & $\Delta$ & $\mathrm{Ws} 2+\mathrm{Wg} 4$ & Wg4 \\
\hline Control field & 437 & 0 & 0 & 52 & 56 & $261(100)$ & $384(100)$ & 123 & $590(100)$ & $206(100)$ \\
\hline SSDC field & 437 & 0 & 149 & 52 & 56 & $259(99)$ & $379(99)$ & 120 & $439(74)$ & $60(29)$ \\
\hline Control field & 3.3 & 0 & 0 & 6.0 & 0 & $93.4(100)$ & $69.7(100)$ & -23.7 & $90.7(100)$ & $21.0(100)$ \\
\hline SSDC field & 3.3 & 0 & 17.2 & 6.0 & 0 & $85.4(91)$ & $60.4(87)$ & -25.0 & $65.5(72)$ & $5.1(24)$ \\
\hline
\end{tabular}

Note: Observation period is from 20 December 2016 to 27 February 2017, for 70 days. Abbreviations: ET is evapotranspiration. W and S represent water amount $(\mathrm{mm})$ and salt mass $\left(\mathrm{Mg} \mathrm{ha}^{-1}\right)$, respectively. Subscripts $i$ is leaching water, $r$ is rain, $g 1$ is groundwater inflow to the root zone, $g 2$ is groundwater outflow from the outlet of the SSDC, $g 3$ is seepage from the field to the open drainage, $g 4$ is groundwater outflow from the root zone through paths other than $g 2$ and $g 3$, et is the evapotranspiration, s1 and $s 2$ represent the storage in the soil before and after leaching. The salt mass of Ss1 and Ss2 is the sum of the salt mass contained within the cubic volume in each $20 \mathrm{~cm}$ of depth, which is derived by multiplying the TDSsoil (\%) with the bulk density $\left(\mathrm{g} \mathrm{cm}^{-3}\right)$ of each root zone.

According to the GWL observation, the leaching raised the GWL. Furthermore, the observation well No.4 showed that the infiltrated water reached the drier neighboring field. The lower Wg4 means a reduction in the downward percolation. Thus, the SSDC may have restricted groundwater recharge in wider parts of the field.

- $\quad$ Remaining salt in the fields: $\mathrm{Ss} 2+\mathrm{S} g 4$

The result of salt balance calculation is also listed in Table 2. The remaining salt, not disposed of to open drainage, was 90.7 and $65.5 \mathrm{Mg} \mathrm{ha}^{-1}$ for the control field and the SSDC field, respectively. The Ss1 
in the root zone of the SSDC field was $8.0 \mathrm{Mg} \mathrm{ha}^{-1}$ less than that of the control field. The difference widened after leaching. The SSDC reduced salt mass a little in the root zone, while the difference in the $\mathrm{Sg} 4$ reached $15.9 \mathrm{Mg} \mathrm{ha}^{-1}, 76 \%$ lower than that of the control field. In the same way as water, the lower $\mathrm{Sg} 4$ for the SSDC field implies that the SSDC restricts the contamination of surrounding fields with salts through horizontal outward flow from the field under leaching.

\section{Discussion}

\subsection{Water and Salt Balance}

Calculated water and salt balance indicate that the SSDC system could enhance the discharge of infiltrated water and salt. The discharged water was highly saline in nature. The differences in EC $w$ between leaching and discharged water indicate that the SSDC removed accumulated salts, showing that the SSDC could assure discharge of groundwater containing much salt even under limited drainage conditions. Discharge from the SSDC was also observed after rain events in March and April when the GWL was high. Therefore, the SSDC system could also promote discharge process under natural precipitation.

Due to enhanced outflow by the SSDC, the remaining water in the SSDC field decreased by $26 \%$ compared with that of the control field. The major portion of this decrease may be due to percolation from the root zone to the deeper zone or neighboring dry field. In other words, the SSDC caught the percolating water and discharged it to the open drainage. Likewise, the remaining salt mass was analogous to the remaining water decrease. The soil salinity had large variation in the control field, the cut-drain part and the area near the drain pipe, respectively, making the difference statistically insignificant. As shown in Figure 9, the upper layer in the cut-drain part and the area near the drain pipe lost more salts than that in the control field. In the root zone, the differences of salt mass between the control field and the SSDC field were small. The leaching would have pushed much salt out of the root zone in both fields. Even under the circumstance of high GWL with high salinity, the famer has practiced leaching to push the salt out of the surface layer, however, the excluded salt remains in the deeper zone or surrounding field due to the limited seepage of groundwater to the open drainage. After leaching, the remaining salt steadily rises to the surface layer with upward flow of water. The reduction in remaining water and salt below the root zone could reduce re-accumulation of salt. The SSDC system was found to fulfill the role for the reduction.

\subsection{Future Development of the SSDC}

The SDGs urges combating desertification and halting and reversing land degradation for sustainable agriculture. To combat desertification, various transitions in the current soil and water system are needed [31]. Innovations in drainage technology are also required to realize the SDGs by 2030. Subsurface drainage is one of the measures to overcome a serious and increasing salinization issue for sustainable development of irrigated agriculture in drylands [32]. It needs more studies for cost reduction and technology sophistication. Viewed in this light, the cut-drain can be an alternative for famers in developing countries because of easy construction using a tractor without any material. The issue of short durability caused by the characteristic of not using reinforcing materials could be solved through incorporating cut-drains into the farming system as a preparation work of the leaching. In addition to that, as a result of the yield survey at the experimental field in September 2017, the cotton yield in the control field, cut-drain part, and near the drain pipe were 3.3, 3.9, and $4.0 \mathrm{Mg} \mathrm{ha}^{-1}$, respectively (Figure S1). The SSDC system gave approximately $18 \%$ higher yield in average compared with the control [26].

To make the effect of the SSDC system more reliable, there are some issues that remain to be resolved. Further studies are needed to clarify the long-term effects, as well as negative effects relating to GWL. Secondly, in this study, seepage rate from the field to the open drainage were estimated based on the observed seepage rate by previous field data in a similar WCA. Thus, there might be 
uncertainty in actual seepage rates including the difference of seepage volumes between the control field and the SSDC field. To analyze water and salt balance more accurately, it would also be necessary to accumulate more drainage discharge data from various fields. Finally, further field experiments with plural repetitions to enable statistical analysis may be required in near future.

\section{Conclusions}

Salinization is one of the drivers of desertification. It is often caused by rising GWL. Drainage systems have been installed to control GWL and leaching is practiced to remove salts from the field. However, the drainage systems are in a state of disrepair in some areas where salinity levels remain high under malfunctioning drainage conditions. To remove accumulated salt, we suggest a low-cost shallow subsurface drainage system used in combination with cut-drains (SSDC). It could be an alternative subsurface drainage technology in drylands. The aim of this study was to evaluate the effect of the system. The experimental field was set with/without the system to observe the differences in the water and salt balance on a farmland in Syrdarya Province, Uzbekistan. It is the first trial to evaluate the effect of cut-drains on shallow subsurface drainage as a salt removal technology in drylands.

The results reveal that the SSDC could reduce accumulated salts, removing $14 \mathrm{Mg} \mathrm{ha}^{-1}$ of salts in net mass, down to approximately between one-third and one-fourth of remaining salt of the control field. The reduction in salts in the root zone was slightly larger than the control field. The most beneficial part of the reduction could be in the deeper zone or surrounding fields. The reduction in remaining salt under the SSDC system could reduce re-accumulation of salt. This implies that the technology can be a means to enhance salt removal from the field. The low-cost and easy construction of the cut-drain can be an advantage for farmers. Although more studies are necessary in terms of long-term effect and more accurate water and salt balance analysis, we expect that the SSDC will contribute to mitigating salinization and benefiting farmers who struggle with the difficulty of salinization.

Supplementary Materials: The following are available online at http://www.mdpi.com/2073-4441/12/11/3207/s1, Table S1: Estimation of groundwater seepage from the field to the open drainage (Wg3), Figure S1: Cotton yield in the experimental field, 2017.

Author Contributions: All authors substantially contributed to conceiving the experiment and realizing this manuscript. Y.O. designed this study; Y.O. and J.O. were in charge of the study administration and collected field data; Y.I.S. analyzed the soil and water; Y.O. prepared the original draft; H.F., Y.K. and I.K. reviewed and edited the manuscript; I.K. developed cut-drains used in the study. All authors have read and agreed to the published version of the manuscript.

Funding: This study was partially funded by an overseas agricultural research project under the Ministry of Agriculture, Forestry and Fisheries, Japan. The study work was conducted as a research project in the Resource Management in Asia and Pacific Islands by the Japan International Research Center for Agricultural Sciences.

Acknowledgments: We gratefully acknowledge the Farmers' Council of Uzbekistan as a research counterpart, the Research Institute of Irrigation and Water Problems of Uzbekistan, the Hydro-Geology Melioration Expedition and farmers in Syrdarya Province, Uzbekistan. We would also appreciate all the parties concerned for their support to this study.

Conflicts of Interest: The authors declare no conflict of interest.

\section{Abbreviations}

The following abbreviations are used in this manuscript.

DWL Drainage water level

ECe Electric conductivity of a saturated extract

EC1:1 Electric conductivity of a 1:1 suspension

ET Evapotranspiration

ET0 Reference evapotranspiration

GWL Groundwater level

SDGs Sustainable Development Goals 
Sg1 Salt mass in groundwater inflow to the root zone $(0-100 \mathrm{~cm})$

$\mathrm{Sg} 2 \quad$ Salt mass in groundwater outflow from the outlet of the SSDC

$\mathrm{Sg} 3 \quad$ Salt mass in groundwater outflow by seepage from the field to the open drainage

Sg4 Salt mass in groundwater outflow from the root zone $(0-100 \mathrm{~cm})$ into the deeper zone or

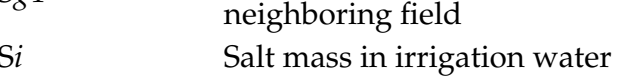

$\mathrm{Sr} \quad$ Salt mass in rain water

Ss1 Salt mass in root zone $(0-100 \mathrm{~cm})$ before leaching

Ss2 Salt mass in root zone $(0-100 \mathrm{~cm})$ after leaching

SSDC Shallow subsurface drainage with cut-drains

TDS Total dissolved solid in the water

TDSsoil Total dissolved solid in the soil

WCA Water Consumers' Association

Wd Amount of water of surface discharge water from the field

Wet Amount of water of evapotranspiration

Wg1 Amount of groundwater inflow to the root zone $(0-100 \mathrm{~cm})$

Wg2 Amount of groundwater outflow from the outlet of the SSDC

Wg3 Amount of groundwater outflow by seepage from the field to the open drainage

Wg4 Amount of groundwater outflow from the root zone $(0-100 \mathrm{~cm})$ into the deeper zone or neighboring field

Wi Amount of irrigation water

Wr Amount of rain water

Ws1 Amount of water in root zone $(0-100 \mathrm{~cm})$ before leaching

Ws2 Amount of water in root zone $(0-100 \mathrm{~cm})$ after leaching

\section{References}

1. Dukhovny, V.; Umarov, P.; Yakubov, H.; Madramootoo, C.A. Drainage in the Aral Sea Basin. Irrig. Drain. 2007, 56, 91-100. [CrossRef]

2. Dukhovny, V.A.; Yakubov, K.I.; Umarov, P.D. Drainage and salinity control: Review of related problems in Central Asia. In Irrigation Management for Combating Desertification in the Aral Sea Basin. Assessment and Tools; Pereira, L.S., Dukhovny, V.A., Horst, M.G., Eds.; Vita Color: Tashkent, Uzbekistan, 2005; pp. 249-270.

3. Qushimov, B.; Ganiev, I.M.; Rustamova, I.; Haitov, B.; Islam, K.R. Land Degradation by Agricultural Activities in Central Asia. In Climate Change and Terrestrial Carbon Sequestration in Central Asia, 1st ed.; Lal, R., Suleimenov, M., Stewart, B.A., Hansen, D.O., Doraiswamy, P., Eds.; Taylor \& Francis: London, UK, 2007; pp. 137-146.

4. Kulmatov, R. Problems of Sustainable Use and Management of Water and Land Resources in Uzbekistan. JWARP 2014, 6, 35-42. [CrossRef]

5. Bucknall, J.; Klytchnikova, I.; Lampietti, J.; Lundell, M.; Scatasta, M.; Thurman, M. Irrigation in Central Asia, Social, Economic and Environmental Considerations; World Bank: Washington, DC, USA, 2003.

6. UNCCD. Global Land Outlook, 1st ed.; United Nations Convention to Combat Desertification: Bonn, Germany, 2017; pp. 246-269.

7. Keesstra, S.; Mol, G.; de Leeuw, J.; Okx, J.; Molenaar, C.; de Cleen, M.; Visser, S. Soil-Related Sustainable Development Goals: Four Concepts to Make Land Degradation Neutrality and Restoration Work. Land 2018, 7, 133. [CrossRef]

8. Keesstra, S.D.; Bouma, J.; Wallinga, J.; Tittonell, P.; Smith, P.; Cerdà, A.; Montanarella, L.; Quinton, J.N.; Pachepsky, Y.; van der Putten, W.H.; et al. The significance of soils and soil science towards realization of the United Nations Sustainable Development Goals. Soil 2016, 2, 111-128. [CrossRef]

9. Khamraev, S.R.; Dukhovny, V.A.; Kadyrov, A.A.; Sokolov, V.I. (Eds.) Water Resources Management in Uzbekistan, 1st ed.; GWP CACENA: Tashkent, Uzbekistan, 2011; pp. 25-65.

10. Frenken, K. Irrigation in Central Asia in figures AQUASTAT Survey-2012. FAO Water Rep. 2013, 39, $183-197$.

11. Okuda, Y.; Onishi, J. Current Status and Problems of Farmland Damage from Salinization in Uzbekistan. J. JSIDRE 2012, 80, 3-6. (In Japanese) 
12. Okuda, Y.; Onishi, J.; Omori, K.; Oya, T.; Fukuo, A.; Kurvantaev, R.; Shirokova, Y.; Nasonov, V. Current Status and Problems of the Drainage System in Uzbekistan. Trans. JALS 2015, 25, 81-84.

13. Okuda, Y.; Onishi, J.; Omori, K. Actual Condition of Vertical Drainage for Farmland Salinization in Republic of Uzbekistan. J. JSIDRE 2015, 83, 21-24. (In Japanese)

14. Kaneko, T.; Murakawa, M.; Kozai, N.; Mitsugi, K. Desalting Technique for Illuviated Salts Soil at Paddy Field by Using Underdrainage. J. JSIDRE 2002, 70, 27-30. (In Japanese)

15. Chiba, K.; Kato, T.; Togashi, C.; Kanmuri, H. Effectiveness of Desalinization by Infiltration of Water and Desalinization of Tsunami-hit Farmlands in Miyagi Prefecture. J. JSIDRE 2012, 80, 3-6. (In Japanese)

16. Ritzema, H.P.; Satyanarayana, T.V.; Raman, S.; Boonstra, J. Subsurface drainage to combat waterlogging and salinity in irrigated lands in India: Lessons learned in farmers' fields. Agric. Water Manag. 2008, 95, 179-189. [CrossRef]

17. Kitagawa, I.; Tsuneta, D.; Haraguchi, N.; Wakasugi, K. Low-cost Drainage Technologies of Realizing Agricultural Infrastructure Improvements for High-Yielding Farm Land. J. JSIDRE 2010, 78, 7-10. (In Japanese)

18. Lu, P.; Zhang, Z.; Feng, G.; Huang, M.; Shi, X. Experimental Study on the Potential Use of Bundled Crop Straws as Subsurface Drainage Material in the Newly Reclaimed Costal Land in Eastern China. Water 2018, 10, 31. [CrossRef]

19. Kitagawa, I.; Takeuchi, H.; Kotani, H.; Chiba, Y. Efficacy and Applicability of the Cutting Drain Method in Excavating Underdrains. Trans. JSIDRE 2010, 267, 11-16. (In Japanese)

20. Cavelaars, J.C.; Vlotman, W.F.; Spoor, G. Subsurface Drainage Systems. In Drainage Principles and Applications, 2nd ed.; Ritzema, H.P., Ed.; ILRI: Wageningen, The Netherlands, 1994; pp. 827-929.

21. Yannopoulos, S.I.; Grismer, M.E.; Bali, K.M.; Angelakis, A.N. Evolution of the Materials and Methods Used for Subsurface Drainage of Agricultural Lands from Antiquity to the Present. Water 2020, 12, 1767. [CrossRef]

22. Bezborodov, G.A.; Shadmanov, D.K.; Mirhashimov, R.T.; Yuldashev, T.; Qureshi, A.S.; Noble, A.D.; Qadir, M. Mulching and water quality effects on soil salinity and sodicity dynamics and cotton productivity in Central Asia. Agric. Ecosyst. Environ. 2010, 138, 95-102. [CrossRef]

23. Onishi, J.; Okuda, Y.; Paluashova, G.K.; Shirokova, Y.I.; Kitamura, Y.; Fujimaki, H. Salt pushing effect to the side of the ridge by fixed skip furrow irrigation-Case study in the Republic of Uzbekistan. Trans. JALS 2018, 28, 155-158.

24. Djumaboev, K.; Hamidov, A.; Anarbekov, O.; Gafurov, Z.; Tussupova, K. Impact of Institutional Change on Irrigation Management: A Case Study from Southern Uzbekistan. Water 2017, 9, 419. [CrossRef]

25. Kitamura, Y.; Yano, T.; Honna, T.; Yamamoto, S.; Inosako, K. Causes of farmland salinization and remedial measures in the Aral Sea basin-Research on water management to prevent secondary salinization in rice-based cropping system in arid land. Agric. Water Manag. 2006, 85, 1-14. [CrossRef]

26. Okuda, Y.; Onishi, J.; Shirokova, Y.I.; Kitagawa, I.; Kitamura, Y.; Fujimaki, H. Salt removal technology by shallow subsurface drainage in combination with a cut-drain. Trans. JALS 2018, 28, 127-130.

27. Okuda, Y.; Goto, K.; Kitagawa, I. A Trail of Desalinization by Using Mole-Drain in Republic of Uzbekistan. J. JSIDRE 2015, 83, 7-10. (In Japanese)

28. Okuda, Y.; Fujimaki, H.; Kitamura, Y.; Kitagawa, I. Problems and Measures for the Adoption of Cut-drain and Its Applicability to Soil Conditions in Uzbekistan. Trans. JSIDRE 2017, 305, II_83-II_90. (In Japanese)

29. Okuda, Y. Studies on Applicability and Effect of Shallow Subsurface Drainage with Cut-Drain for Salinized Irrigated Land in Central Asia. Ph.D. Thesis, Tottori University, Tottori, Japan, 13 September 2019 (In Japanese).

30. Shirokova, Y.; Forkutsa, I.; Sharafutdinova, N. Use of electrical conductivity instead of soluble salts for soil salinity monitoring in Central Asia. Irrig. Drain. Syst. 2000, 14, 199-205. [CrossRef] 
31. Visser, S.; Keesstra, S.; Maas, G.; de Cleen, M.; Molenaar, C. Soil as a Basis to Create Enabling Conditions for Transitions towards Sustainable Land Management as a Key to Achieve the SDGs by 2030. Sustainability 2019, 11, 6792. [CrossRef]

32. Kitamura, Y.; Oweis, T.Y. Agricultural Water Management in the Drylands: New Paradigm to Cope with Scarcity and Climate Change; GIHODO SHUPPAN Co., Ltd.: Tokyo, Japan, 2018; pp. 179-194.

Publisher's Note: MDPI stays neutral with regard to jurisdictional claims in published maps and institutional affiliations.

(C) 2020 by the authors. Licensee MDPI, Basel, Switzerland. This article is an open access article distributed under the terms and conditions of the Creative Commons Attribution (CC BY) license (http://creativecommons.org/licenses/by/4.0/). 